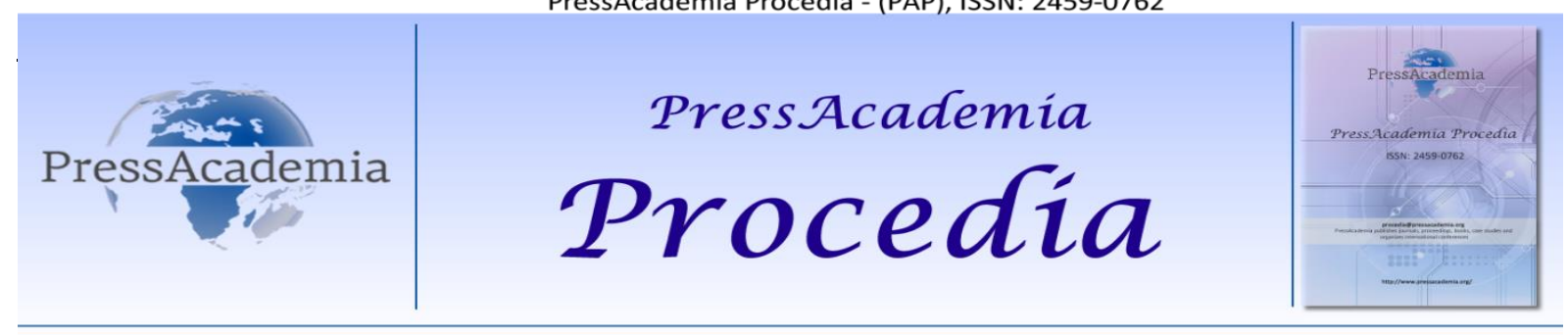

Global Business Research Congress (GBRC), May 24-25, 2017, Istanbul, Turkey.

\title{
ASSESSMENT OF PERSONAL PROTECTIVE EQUIPMENT IN BUSINESSES
}

\section{DOI: 10.17261/Pressacademia.2017.433 \\ PAP-GBRC-V.3-2017(48)-p.488-494}

\section{Mehmet Colak ${ }^{1}$, Sebnem Korkut ${ }^{2}$, Tahsin Cetin ${ }^{3}$}

${ }^{1}$ Muğla Sıtkı Koçman University, Technology Faculty, Kötekli Campus, Muğla, Turkey. cmehmet@mu.edu.tr

${ }^{2}$ Muğla Sıtkı Koçman University, Department of Occupational Safety and Health, Kötekli Campus,Muğla, Turkey. s.sebnemkrkt@gmail.com

${ }^{3}$ Muğla Sıtkı Koçman University, Technology Faculty, Kötekli Campus, Muğla, Turkey. tahsincetin@mu.edu.tr

To cite this document

Çolak, M., S. Korkut and T. Cetin, (2017). Assessment of personal protective equipment in businesses, PressAcademia Procedia (PAP), V.3, p.488-494

Permemant link to this document: $h \mathrm{ttp}: / /$ doi.org/10.17261/Pressacademia.2017.433

Copyright: Published by PressAcademia and limited licenced re-use rights only.

\begin{abstract}
494 occupational illnesses and 1,626 death out of 221,336 occupational accidents occurred in 2014 (TUIK). Personal Protective Equipment (PPE), protects against to health or safety issue based on an occupation, designed for specific aim, can be worn, hold or attached to an employer, have a significant impact for declining the occupational illness/accident. In this study, different types were investigated, and responsibility of employ/employer was assessed. Also, the usages, benefits, and impacts of PPE were evaluated in a site. Data obtained was analyzed with Excel and concluded if PPE is used properly, it protects an employer against to occupational accidents.
\end{abstract}

Keywords: Industrial business, perception of employees, occupational safety factor, personal protective equipment, businesses. JEL Codes: J28, I10, J20

\section{IŞLETMELERDE KiŞiSEL KORUYUCU DONANIM'IN ETKINLIĞiNIN ÖLÇÜLMESi}

\section{ÖZET}

Türkiye İstatistik Kurumu, 494 meslek hastalığı ve 1626 'sı ölümlü 221,366 iş kazası tespit etmiştir (2014). İs kazaları riskini indirgemede kişisel koruyucu donanımın (KKD) önemi büyüktür. KKD, yürütülen işten kaynaklanan sağlığı ve güvenliği etkileyen risklere karşı koruyan, çalışan tarafından giyilen, takılan veya tutulan, bir amaca uygun olarak tasarlanmış alet, araç, gereç ve cihazları ifade eder. Bu çalışmada farkı koruyucu türleri incelenip, koruyucuların kullanımı konusunda işveren ve çalışan sorumlulukları değerlendi. Ayrica, KKD'ın kullanımı, etkileri ve faydaları bir iş sahasında yapılan araştırmayla belirlendi. Veriler Excel programıyla analiz edilmiştir ve KKD'ın doğru şekilde kullanıldığında çalışanı iş kazalarına karşı koruduğu şeklinde sonuçlanmıştır.

Anahtar Kelimeler: Endüstriyel işletmeler, çalışanların algısı, iş güvenliği faktörü, kişisel koruyucu donanım, işletmeler. JEL Kodları: J28, I10, J20

\section{GíRiş}

İ̧̧ yerlerinde iş sağlığı ve güvenliğinin sağlanması, sağlıklı ve güvenli çalışma ortamlarının oluşturulması için risklere karşı koruyucu ve önleyici tedbirlerin alınması ve mevcut sağlık ve güvenlik şartlarının iyileştirilmesi gerekmektedir. Risk değerlendirmesi yapılarak çalışanların maruz kalabilecekleri tehlikelere karşı alınacak koruyucu ve önleyici tüm tedbirler, risklere kaynağında müdahale edilmesi yoluyla ve toplu korunma tedbirleri öncelikli olarak alınmalıdır. Kişisel koruyucu 
donanımlar, çalışanların sağlıklı ve güvenli olarak çalışmalarını sağlamak amacıyla, gerek kaynağında kontrol altına alınamayan risklere karşı koruyucu olarak, gerekse mevcut şartları daha iyiye taşımak için kullanılabilecek ürünlerdir (Öymez, 2017).

\section{LITERATURE INCELEMESI}

Sosyal Güvenlik Kurumu'nun iş kazaları ve meslek hastalıklarına ilişkin (2014) yılı istatistiklerine göre 221 bin 366 iş kazası yaşandı, 494 meslek hastalığı tespit edildi. Bunların 1.626'sı ölümle sonuçlandı. Bu sebeple iş kazaları riskini en aza indirgemede kişisel korucunun donanımların önemi büyüktür. Kişisel Koruyucu Donanım (KKD), çalışanı yürütülen işten kaynaklanan sağlık ve güvenliği etkileyen bir veya birden fazla riske karşı koruyan, çalışan tarafından giyilen, takılan veya tutulan, bir amaca uygun olarak tasarımı yapılmış tüm alet, araç, gereç ve cihazları ifade eder. Kişisel koruyucu donanımın hangi riske karşı koruma sağladığı önem taşır (Anonim 1, 2009).

\section{Şekil 1. Çeşitli Kişisel Koruyucu Donanımlar}

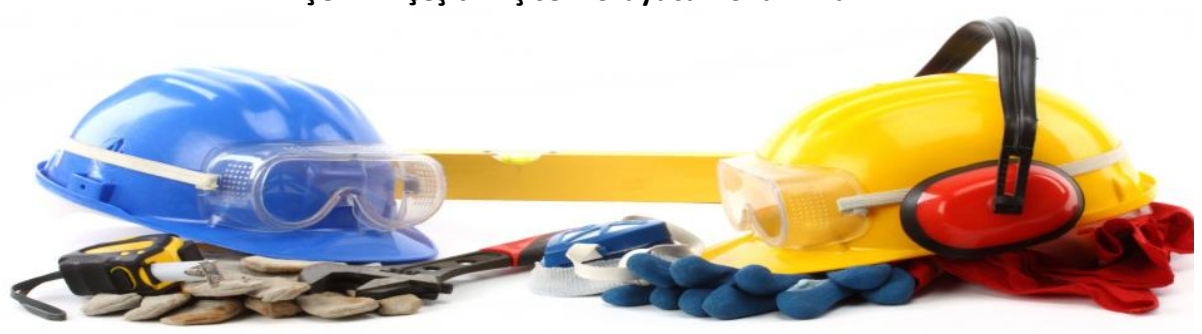

Söz konusu risklere göre göz-yüz koruyucuları, kulak koruyucuları, baş koruyucuları, el-kol koruyucuları, ayak-bacak koruyucuları, vücut ve gövde koruyucuları ve solunum sistemi koruyucuları olarak türlere ayrılır. Bu riskler göz önünde bulundurularak doğru yerde doğru ekipmanın kullanılması önem taşır. KKD ile ilgili bir diğer husus, kullanım kolaylığının olmasıdır. Eğer KKD kullanışı ve konforlu olursa, tehlikenin mevcut olduğu durumlarda kullanım sürekliliğinin olması halinde olası riskler en aza indirgenir. Buna göre, bir kişinin KKD etkinliğinin kanıtlandığı nokta, donanımı giymek ya da kullanmak için ikna edilmesidir (Hale ve Glendon, 1987).

Şekil 2. Kișisel Koruyucu Simgeleri

(1)

Uygun KKD’nin kullanımı açısından işçi eğitiminin gerekliliği açıktır. KKD’ye ihtiyaç olduğu saptanırsa, donanımı uygun şekilde kullanmaya ilişkin eğitimin yapılması zorunlu ve kaçınılmazdır. Iş̧̧i bu eğitim ile KKD'nin ne zaman gerekli olduğunu, ne tür KKD’ye ihtiyaç duyulduğunu, donanımı doğru şekilde nasıl giyeceğini (Asfahl, 2004), donanımın sınırlılıklarını ve bakımını nasıl uygun şekilde yapacağını öğrenecektir. Belirtmek gerekir ki, bir işçi KKD eğitimi görmüş olsa bile, işyeri ya da KKD değişirse, işveren sorumluluğu gereği işçiyi yeniden eğitmelidir (Demirbilek ve Çakır, 2008).

Uygun KKD kullanımına yönelik işçi tutumu, büyük ölçüde işletme yönetiminin tutumundan etkilenmektedir. Nezaretçiler (ilk amir), bir rol modeli olarak yol gösterici olmalıdır. Uygun KKD’lerin neler olduğunun işyerinde saptanması ile işçilerin KKD 
eğitimine tabi tutulmasının yanında, KKD kullanımını destekleyen yazılı politikalar da olmalıdır (Wentz, 1998). Bu anlamda, bir KKD programı donanımın ne zaman ve ne türde kullanılması gerektiğini belirleyen kuralları bütünüyle uygulatmalıdır. Söz konusu uygulatma, işyerinin iş güvenliği denetim sisteminin yeterliliğine bağlıdır. KKD programı; sorumluluğu, mevcut olmayı, uygunluğu ve bakımı içermelidir (Weinstein, 1997).

\section{VERI VE YÖNTEM}

Araştırmada, işyerinde iş sağlığı ve güvenliği uygulamaları konusunda çalışan işçilerin tutumları, davranışları, güvenlikli kişisel koruyucu donanım kullanım ihtiyacları ve yöneticilerin konuyla ilgili yaklaşım ve uygulamalarının işçi bakımından algılanışının belirlenmesi amaçlanmıştır. Bu kapsamda araştırmanın temel çıkış noktası güvenli iş davranışın bir göstergesi olarak "kişisel koruyucu donanım kullanımı" faktörüne iş̧̧ilerin davranışları oluşturmuştur.

Bu çalışma anket tekniği ile gerçekleştirilmiştir. Anket verileri Excel (2010) programında analiz edilmiştir. Araştırma verileri iç ve dış piyasa için üretim yapan bir polyester fabrikasından toplanmıştır. Kişisel koruyucu donanım (KKD) kullanan 100 işçiye anket uygulanması sonucunda 80 anketten kullanılabilir veri elde edilmiştir. Bu çalışmada, işyerinde iş sağlığı ve güvenliği kapsamında KKD kullanımı ile ilgili çalışanların görüşleri alınmıştır.

\section{BULGULAR VE TARTIŞMA}

Ankete katılanlar ile ilgili demografik bilgiler ile betimleyici istatiksel veriler aşağıdaki tablolarda verilmiştir.

Tablo 1: Örneklem Ile ilgili Demografik Veriler

\begin{tabular}{|c|c|c|c|}
\hline & & Sayı & Yüzde (\%) \\
\hline \multirow{5}{*}{ Yaş } & $18-26$ yaş & 19 & 23,75 \\
\hline & $27-34$ yaş & 33 & 41,25 \\
\hline & $35-43$ yaş & 16 & 20 \\
\hline & 44 ve üstü & 7 & 8,75 \\
\hline & Belirtmeyen & 5 & 6,25 \\
\hline \multirow{2}{*}{ Medeni Durum } & Evli & 52 & 65 \\
\hline & Bekar & 28 & 35 \\
\hline \multirow{5}{*}{ İş Deneyimi } & 1 yıldan az & 12 & 15 \\
\hline & 1-5 yıl & 24 & 30 \\
\hline & 6-10 yıl & 16 & 20 \\
\hline & 11-15 yıl & 18 & 22,5 \\
\hline & 15 yıldan fazla & 10 & 12,5 \\
\hline \multirow{2}{*}{ Çalışılan Kısım } & Demirhane & 32 & 40 \\
\hline & Polyester & 48 & 60 \\
\hline
\end{tabular}

Tablo 1'de elde edilen verilere göre; katılımcıların yaklaşık \%25'i genç iş gören ve \%50'ye yakınının iş deneyiminin 5 yıldan az olması kişisel korunma donanım kullanım alışkanlığı kazanması bakımından önemlidir. Çünkü genç çalışanların başlangıçta kazanacağı alışkanlık ve uyacağı iş sağlığı güvenliği davranışları kazaları önleme adına dikkat çekicidir.

Tablo 2: Çalışma Ortamı ile ilgili Veriler

\begin{tabular}{|l|l|l|l|}
\hline \multicolumn{2}{|c|}{} & Sayı & Yüzde (\%) \\
\hline \multirow{3}{*}{ İşyeriniz güvenli mi? } & Evet & 43 & 53,75 \\
\cline { 2 - 4 } & Kısmen & 27 & 33,75 \\
\cline { 2 - 4 } & Hayır & 10 & 12,5 \\
\hline \multirow{3}{*}{ Çalıştı̆̆ınız bölümde kendinizi güvende hissediyor musunuz? } & Evet & 19 & 23,75 \\
\cline { 2 - 4 } & Kısmen & 42 & 52,5 \\
\cline { 2 - 4 } & Hayır & 19 & 23,75 \\
\hline
\end{tabular}




\begin{tabular}{|c|c|c|c|}
\hline \multirow{3}{*}{$\begin{array}{l}\text { Çalıştığınız bölümün fiziksel imkanları (aydınlatma, ısınma, } \\
\text { gürültü vb.) çalışmaya elverişli mi? }\end{array}$} & Evet & 38 & 47,5 \\
\hline & Kısmen & 29 & 36,25 \\
\hline & Hayır & 13 & 16,25 \\
\hline \multirow{3}{*}{ Çalışığınız bölümde iş güvenliği önlemleri yeterli mi? } & Evet & 34 & 42,5 \\
\hline & Kısmen & 38 & 47,5 \\
\hline & Hayır & 8 & 10 \\
\hline \multirow{3}{*}{$\begin{array}{l}\text { Çalışan güvenliği için gerekli kişisel donanımlar temin edilmiş } \\
\text { mi? }\end{array}$} & Evet & 33 & 41,25 \\
\hline & Kısmen & 41 & 51,25 \\
\hline & Hayır & 6 & 7,5 \\
\hline \multirow{3}{*}{$\begin{array}{l}\text { Kişisel koruyucu donanımları kullanmanız için teşvik edici } \\
\text { tabela ve posterler bulunuyor mu? }\end{array}$} & Evet & 52 & 65 \\
\hline & Kısmen & 21 & 26,25 \\
\hline & Hayır & 7 & 8,75 \\
\hline
\end{tabular}

Tablo 2'de elde edilen verilere göre; katılımcıların yaklaşık \%85'i çalıştığı işyerinin güvenli olduğunu, yaklaşık \%90'ı çalışan güvenliği için gerekli donanımların temin edildiğini ve bu donanımların kullanımı için teşvik edici tabela ve posterler bulunduğunu belirtmiştir.

Kişisel koruyucularla ilgili toplanan veriler aşağıdaki gibidir.

Tablo 3: Kişisel Koruyucu Donanımlar ile İlgili Veriler

\begin{tabular}{|c|c|c|c|}
\hline & & Sayı & Yüzde (\%) \\
\hline \multirow{3}{*}{$\begin{array}{l}\text { Çalışan güvenliği için gerekli kişisel donanımları } \\
\text { kullanıyor musunuz? }\end{array}$} & Evet & 49 & 61,25 \\
\hline & Kismen & 23 & 28,75 \\
\hline & Hayır & 8 & 10 \\
\hline \multirow{3}{*}{ Bu donanımlar uygun standartlara sahip mi? } & Evet & 22 & 27,5 \\
\hline & Kısmen & 49 & 61,25 \\
\hline & Hayır & 9 & 11,25 \\
\hline \multirow{3}{*}{$\begin{array}{l}\text { Bu donanımlar yeterli miktarlarda sağlanıyor } \\
\text { mu? }\end{array}$} & Evet & 28 & 35 \\
\hline & Kısmen & 41 & 51,25 \\
\hline & Hayır & 11 & 13,75 \\
\hline \multirow{3}{*}{$\begin{array}{l}\text { Bu donanımları doğru ve amacına uygun şekilde } \\
\text { kullanıyor musunuz? }\end{array}$} & Evet & 37 & 46,25 \\
\hline & Kismen & 36 & 45 \\
\hline & Hayır & 7 & 8,75 \\
\hline \multirow{3}{*}{$\begin{array}{l}\text { Kullandığınız kişisel koruyucu donanımın } \\
\text { konforlu ve kullanışlı olması önemli bir etken } \\
\text { midir? }\end{array}$} & Evet & 36 & 45 \\
\hline & Kısmen & 30 & 37,5 \\
\hline & Hayır & 14 & 17,5 \\
\hline \multirow{3}{*}{$\begin{array}{l}\text { Bu donanımların iş kazası riskini azalttığını } \\
\text { düşünüyor musunuz? }\end{array}$} & Evet & 34 & 42,5 \\
\hline & Kısmen & 40 & 50 \\
\hline & Hayır & 6 & 7,5 \\
\hline \multirow{2}{*}{$\begin{array}{l}\text { Bu donanımların meslek hastalığı riskini } \\
\text { azalttığını düşünüyor musunuz? }\end{array}$} & Evet & 42 & 52,5 \\
\hline & Kismen & 27 & 33,75 \\
\hline
\end{tabular}




\begin{tabular}{|l|l|l|l|} 
& Hayır & 11 & 13,75 \\
\hline \multirow{4}{*}{$\begin{array}{l}\text { En çok sizi koruduğunu düşündüğünüz kişisel } \\
\text { koruyucu donanım hangisi? }\end{array}$} & Tulum & 6 & 7,5 \\
\cline { 2 - 4 } & Maske & 24 & 30 \\
\cline { 2 - 4 } & Eldiven & 7 & 8,75 \\
\cline { 2 - 4 } & Koruyucu Gözlük & 9 & 11,25 \\
\cline { 2 - 4 } & İş Ayakkabısı & 34 & 42,5 \\
\hline
\end{tabular}

Tablo 3'de elde edilen verilere göre; katılımcıların yaklaşık \%90'ı çalışan güvenliği içi gerekli kişisel donanımları kullandığını fakat bu donanımların uygun standartlara sahip olmadığını belirtmiştir. Her ne kadar yeterli miktarda iş̧̧ilere bu donanımlar sağlansa da uygun standartlara sahip olması ayrıca önemlidir. Bu donanımların iş kazası ve meslek hastalığı riskini büyük oranda $(\% 92,5)$ azalttığı, ve en çok çalışanı koruyan donanımın yüz hava maskesi ile iş ayakkabısının olduğu elde edilen sonuçlar arasındadır.

Ayrıca grafiksel olarak verilere bakıldığında katılımcıların $\% 52,5$ 'i çalıştığı bölümde kısmen güvende hissederken $\% 27,5$ güvende hissettiğini geri kalan $\% 27,5$ güvende hissetmediğini belirtmiştir.

\section{Grafik 1: Çalışılan Bölümde Güvende Hissetme}

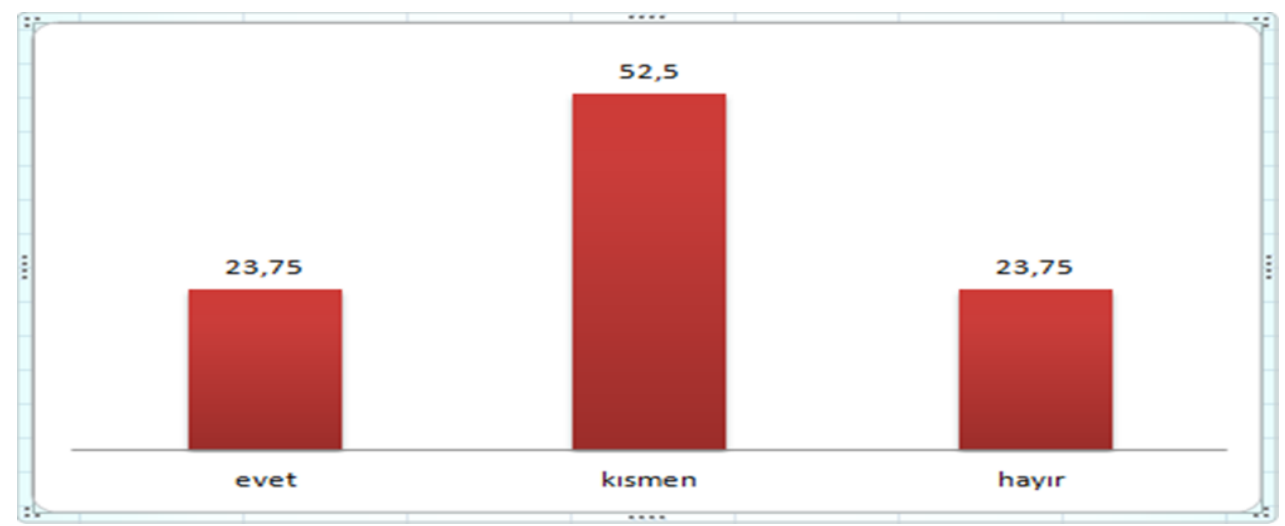

Çalışan güvenliği için gereken Kişisel koruyucuların kullanıp kullanılmadığı sorulduğunda \%61,25'i kullandığını söylerken \%28.75'i kısmen kullandığını belirtmiştir.

\section{Grafik 2: KKD Kullanım Oranı}

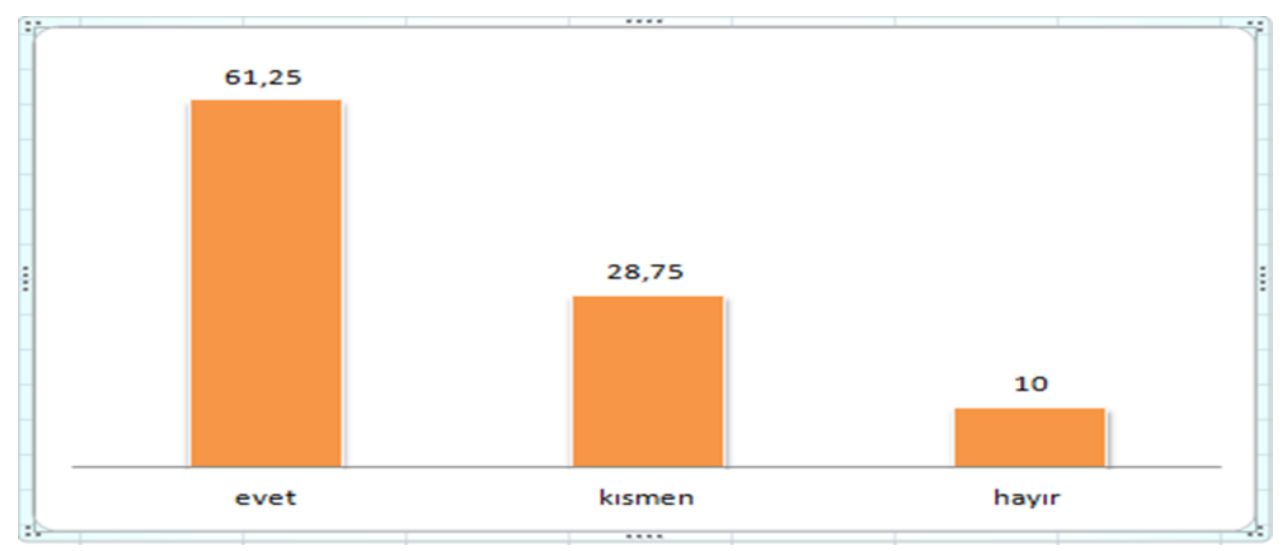

Katılımcıların \%46,25’i kullandıkları donanımları doğru ve amacına uygun olarak kullandığını belirtmiştir. 


\section{Grafik 3: KKD’ın Kullanım Etkinliği}

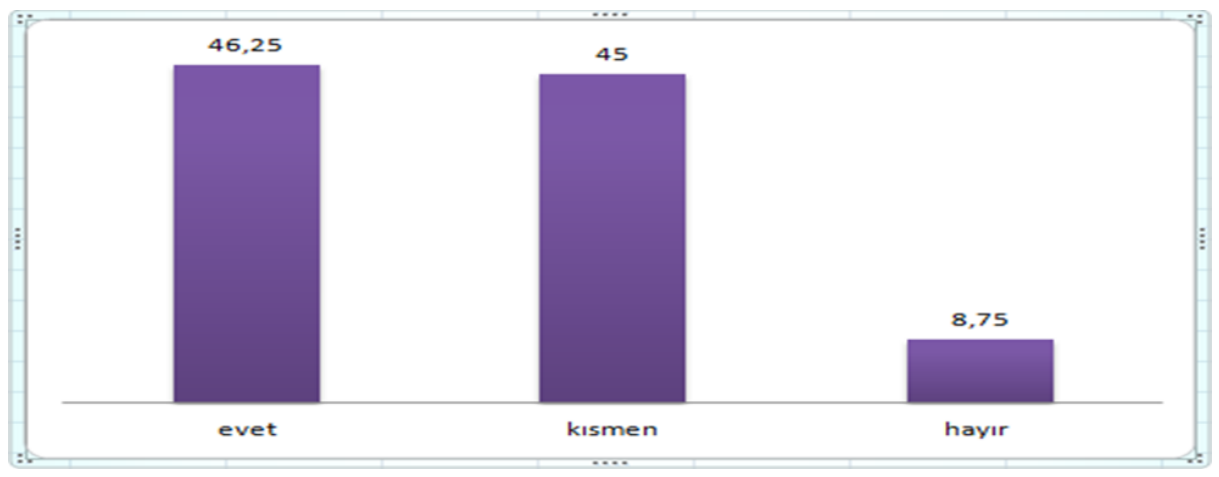

KKD’nin kullanım devamlılığının sağlanmasında kullanışlı ve konforlu olması katılımcıların \% 45'i için önemli bir unsurdur.

\section{Grafik 4: KKD’nin Kullanım Kolaylığı}

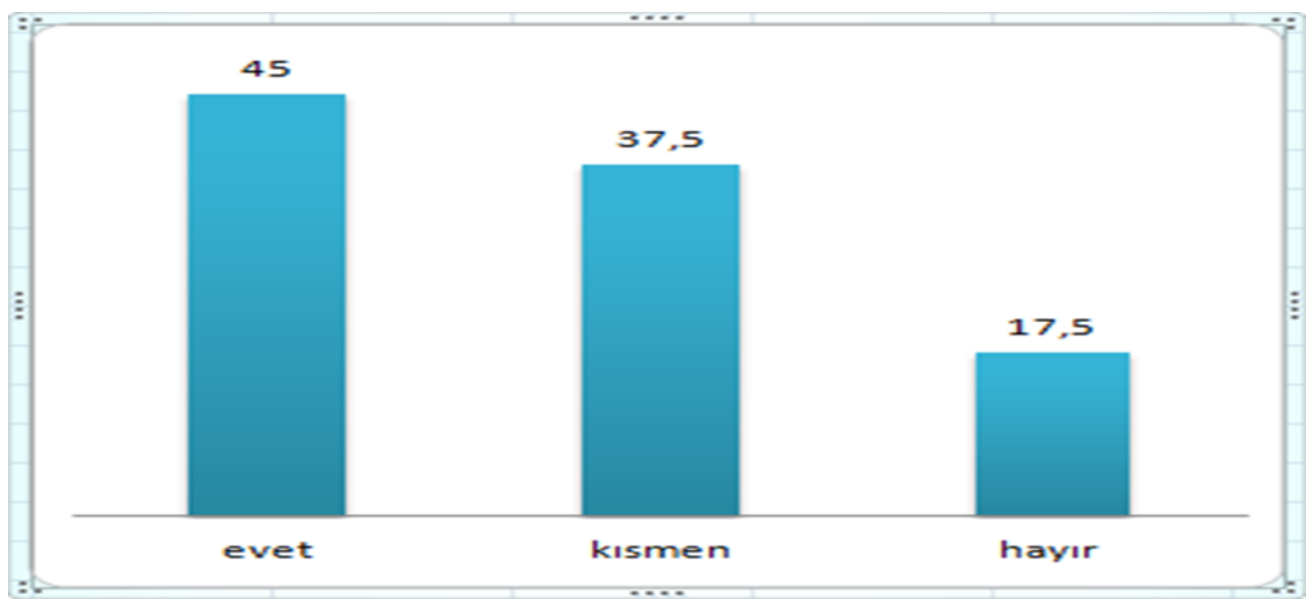

Katıımcıların \%50'si KKD’nin iş kazası riskini kısmen azalttığını belirtmiştir.

\section{Grafik 5: KKD Kullanımının İ̧̧ Kazasına Etkisi}

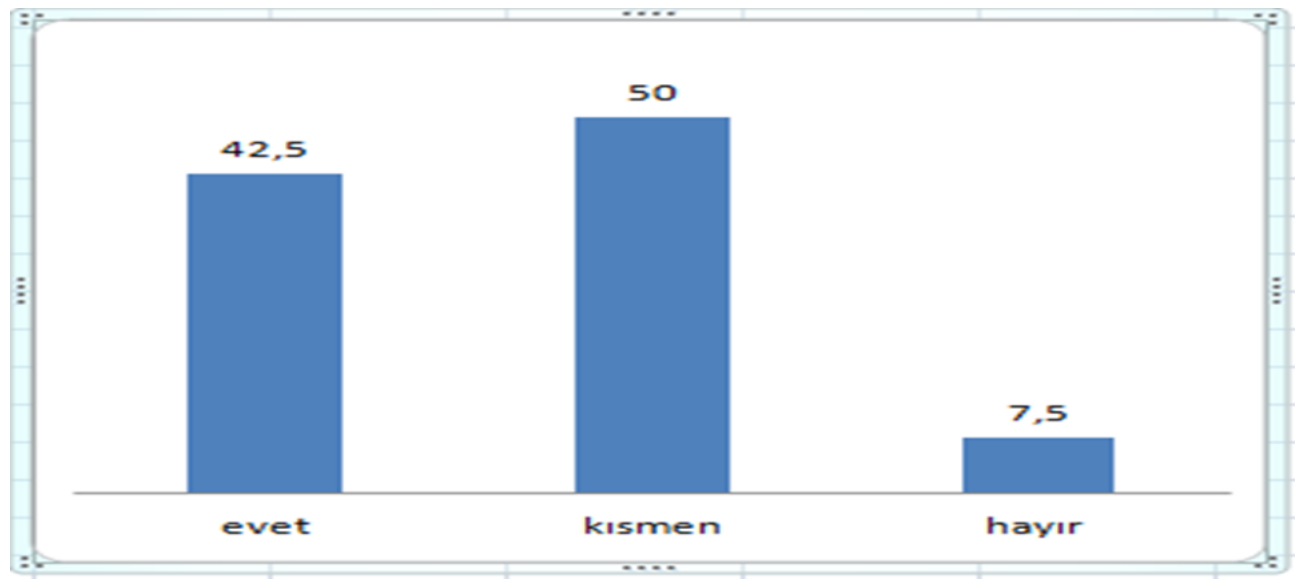

Tüm koruyucu ve önleyici tedbirler alınmış olmasına rağmen, riskin yüksek olduğu durumlarda ekipman ya da güvensiz davranış kusurlarından oluşabilecek tehlikelere karşı ya da ihmal ihtimali veya farkındalığın düşük olduğu çalışma koşullarında yine son tedbir olarak KKD kullanımı önemlidir (Öymez, 2017). 


\section{SONUÇ}

İş kazası riskini en aza indirgemede Kişisel Koruyucu Donanım kullanımının (KKD) önemi büyüktür. Kişisel Koruyucu Donanım kullanımının sağlanması için, kullanılması gereken Kişisel Koruyucu Donanımlar çalışılan ortamın riskleri göz önüne alınarak seçilmelidir. Çalışılan ortamda güvende hissettirmelidir. Kullanım sürekliliği olması için çalışan açısından konforlu ve kullanışlı olması önem taşımaktadır. Eğer çalışan kullandığı koruyucu içinde kendisini güvende hissediyor ve koruyucu iş yapmasına engel olmuyorsa Kişisel Koruyucu Donanımın kullanım etkinliği artar. İş kazaları risklerinin de önüne geçilmesine yardımcı olur.

İş̧iler Kişisel Koruyucu Donanım kullanma gereksinimini algılarsa, nasıl kullanacağını bilirse ve donanımın fayda ve sınırılıkları hakkında bilgi sahibiyse, donanım tam manasıyla koruyucu olabilir (Demirbilek ve Çakır, 2008).

Kişisel Koruyucu Donanımın kullanımı ve özellikle doğru kullanımı için yönetsel ve örgütsel çalışmalar yapılmalıdır. Yapılan araştırmalar göstermiştir ki Kişisel Koruyucu Donanımın kullanımında yönetimin, yöneticilerin örnek davranışları, teşvik edici uygulamaları, diğer kullanıılar, ödül ve ceza yaptırımlarının etkisi yüksektir. Eğitimler ile Kişisel Koruyucu Donanımı neden kullanması gerektiğini öğrenen kullanıcı, kendisine hızlı temin edebileceği yakın bir noktada, kolay giyilen, takılan veya elde taşınan, konforlu, kullanım kolaylığı olan Kişisel Koruyucu Donanım temin edildiğinde, hem kendisi isteyerek hem de diğer kullanıcıları olumlu yönde etkileyerek KKD'yı doğru kullanmaktadır. Rol model olan birinci derece amirler ile diğer çalışma arkadaşları bu konuda yol gösterici olmaktadırlar. Doğru kişisel koruyucu donanım seçilmeli ve seçilen kişisel koruyucu donanım çalışanın maruziyeti süresince, kullanım talimatlarına uygun olarak, doğru şekilde kullanılmalıdır (Öymez, 2017).

Ülkemizde iş kazalarının azaltılarak, güvenli çalışma ortamları yaratılabilmesi için, yürürlükte olan yasa, tüzük ve yönetmeliklerin titizlikle uygulanması gereklidir. Yöneticilerinin iş güvenliği konusuna gereken ilgiyi göstermesi, iş sağlığı ve güvenliği konusunda bilgiye sahip olmaları ve konuya gerekli özeni göstermeleri, çalışanların güvenli davranış sergilemelerini teşvik edecek önemli ön koşullar olarak görülmelidir. Böyle bir anlayışla, iş güvenliği eğitimine ağırlık verilmesi ve özellikle iş güvenliğine yönelik eğitimlerde güvensiz davranışlar ve yol açabileceği sonuçlar üzerinde önemle durulmalıdır (Demirbilek ve Çakır, 2008).

Bu çalışma Muğla Sıtkı Koçman Üniversitesi III. Fen Bilimleri Araştırma Sempozyumunda Özet Poster Olarak Sunulmuştur (05.05.2016).

\section{KAYNAKLAR}

ANONiM 1, (2009), Mühendis ve Makina Dergisi Cilt: 50, Sayı: 592, ss: 33-36.

ASFAHL, C. Ray (2004), Industrial Safety and Health Management, Fifth Edition, Pearson Prentice Hall, Upper Saddle River.

DEMiRBiLEK, T., ÇAKIR, Ö., (2008), Kişisel Koruyucu Donanım Kullanımını Etkileyen Bireysel ve Örgütsel Değişkenler Dokuz Eylül Üniversitesi İktisadi ve İdari Bilimler Fakültesi Dergisi Cilt:23 Sayı:2, ss:173-191.

HALE, Andrew R. ve GLENDON, A. Ian (1987, Individual Behaviour in the Control of Danger, Elsevier Science Publishers, Amsterdam.

ÖYMEZ, Y., (2017), İş Sağlığı ve Güvenliği, Kişisel Koruyucu ve Donanımlar 13. Ünite, Atatürk Üniversitesi Açıöğretim Fakültesi, Erzurum.

TÜiK, (2015), İş Kazaları ve Meslek Hastalıkları İstatistikleri Erişim: (24.04.2015).

T.C. Resmi Gazete, İş Sağlığı ve İş Kanunu.

T.C. Resmi Gazete, Kişisel Koruyucu Donanımların İşyerlerinde Kullanılması Hakkında Yönetmelik-2016.

WEINSTEIN, Michael B., (1997), Total Quality Safety Management and Auditing, Lewis Publishers, Boca Raton.

WENTZ, Charles A., (1998), Safety, Health and Environmental Protection, McGraw-Hill Book Company, Boston. 